\title{
Medical Tourism Overseas: A Challenge to Kuwait's Healthcare System
}

\author{
Bader Alhendi ${ }^{*}$, Saleh Al-Saifi ${ }^{1}$, Aliaa Khaja ${ }^{1}$ \\ 'Department of Orthopedic, Razi Hospital, Ministry of Health, Kuwait City, Kuwait
}

Corresponding Author: Bader Alhendi, MD, Department of Orthopedic, Razi Hospital, Ministry of Health, Kuwait City, Kuwait. Tel: +965-99663262, Email: baderalhendi@rcsi.ie

Received September 16, 2019; Accepted February 8, 2020; Online Published March 11, 2020

\begin{abstract}
Introduction: The State of Kuwait spends large sums of governmental funds on sending patients abroad to receive medical treatment. This study aimed to explain the rationale behind receiving primary medical care overseas, given the expense and inconvenience, from the perspective of Kuwaiti patients whose applications were approved.

Methods: The survey was designed based on recommendations from an expert panel of physicians working in Kuwait and aimed to give insight into outbound medical services as perceived by the Kuwaiti population. Using Google Forms, the survey was sent electronically to 1067 patients who received treatment abroad sponsored by the government in the year 2018, and 590 responses were returned. The study itself explored reasons for seeking treatment abroad, finances, preferred countries, and whether there were touristic reasons behind such practice. Data was analyzed using SPSS version 26.

Results: Overall, males (52.3\%) and females (47.7\%) were equally represented in the study sample. The mean age for the study sample was $41 \pm 13.4$ years. Approximately $45.3 \%$ of the respondents were married and had children. Of the remaining respondents, $21.9 \%$ were married with no children and $23.8 \%$ were single without children. All respondents received medical treatment abroad, and $52.3 \%$ of the married respondents and $47.7 \%$ of the single respondents stated that they received treatment once and more than once, respectively. Conclusion: Most Kuwaiti citizens do not have faith in the Kuwaiti medical system. Therefore, heavy investments are needed to send patients abroad.

Keywords: Treatment Abroad, Medical Tourism, Economic Burden, Kuwait Healthcare
\end{abstract}

Citation: Alhendi B, Al-Saifi S, Khaja A. Medical tourism overseas: a challenge to Kuwait's healthcare system. Int J Travel Med Glob Health. 2020;8(1):22-30. doi:10.34172/ijtmgh.2020.04.

\section{Introduction}

The world is a global village. People, cultures, and nations are becoming more connected, especially in the modern world where technological advancement has occurred. Healthcare systems have also exhibited such changes and are no longer restricted by national borders. Citizens of various countries have the leverage to seek medical care in any country of their choice, even in non-emergency conditions. ${ }^{1}$ The practice of seeking medical care abroad in non-emergency situations is known as medical tourism. ${ }^{2}$ No general term has yet been coined for patients seeking healthcare elsewhere. They are generally referred to as "medical tourists" or "health tourists." However, the use of the term "tourists" suggests that these medical visits are for leisure or pleasure purposes. ${ }^{1-5}$ Many countries have performed thorough evaluations of their healthcare positions because of globalization. $\cdot^{1-5}$ Some nations have inadequate medical facilities, and therefore, patients opt to seek medical treatment in other countries that have better services.

The case of medical tourism in Kuwait has been challenging to determine. Government officials and members of parliament (MPs) have been accused of using medical treatment as a conduit to siphon public funds for travel abroad. The same malpractice has been prevalent in different nations across the world. Despite many claims that there is a decline in outbound medical tourism, given submissions to Parliament revealed that the trend of traveling overseas for medical treatment (with government funds) increased astronomically in 2017.6,7 To slash the cost of sponsoring Kuwaitis abroad for medical treatment, new regulations for overseas treatment was endorsed by the Minister of Health in 2017. In a step toward eradicating corruption and political influence, the use of public funds for overseas treatment was made subject to approval by an independent medical board before the release of funds. ${ }^{6-8}$

The approach led to a political row with board members

Copyright $\odot 2020$ The Author(s). This is an open-access article distributed under the terms of the Creative Commons Attribution License (http:// creativecommons.org/licenses/by/4.0), which permits unrestricted use, distribution, and reproduction in any medium, provided the original work is properly cited. 
accusing government officials and MPs of influencing decisions and using medical treatment as a conduit to siphon public funds for holidays abroad. ${ }^{9}$ Despite claims that there was a decline in medical tourism, figures reported by the Parliament show that the number of people traveling abroad has actually increased; Approximately 12000 people traveled in 2017, and in 2018, people spent 188 million Kuwaiti dinars. The nation accused MPs and other government officials of using government funds to sponsor themselves, their friends, and their families to seek medical treatment abroad. ${ }^{5-9}$ Moreover, a lot of money is spent on catering to medical services inside the nation; yet, the government can develop medical institutions to provide for the needs of the people, regardless of their social, political, or financial status.

Several factors encourage patients and non-patients to seek treatment abroad due to the predicaments faced by various countries. These include easy access to information about foreign medical services, the low cost of transportation across countries, and a reduction in language barriers, all thanks to globalization as well as the unavailability of treatments in the home country (for cultural, legal, or religious reasons), long waiting lists for some medical procedures ${ }^{2}$ (as in Canada), and inadequate insurance health coverage (as in the United States).$^{10-12}$ However, a few barriers were found to hinder medical tourism. For instance, financial costs, lack of confidence in the healthcare system, ill health, unfamiliarity, and discouragement by home-based and family physicians affected the execution of medical services. ${ }^{13}$

People who patronize medical tourism companies purchase a variety of services ranging from cosmetic procedures to organ transplants, orthopedic procedures, and cancer therapies. The costs of medical tourism packages vary, depending on destination, the type of medical procedures, duration of stay, and accommodations. ${ }^{14}$

Some ethical issues have also been raised concerning medical travel. This is more evident when health policies vary in a particular country, especially with packages that differ for citizens and foreigners. Informed consent constitutes a critical legal and ethical issue as it requires medical tourism companies to explain the risks and benefits of medical treatment overseas to the patients. ${ }^{13}$ Other ethical concerns include disruption of care for patients and exacerbation of medical inequities in source and destination countries.

The current study was designed to investigate why the public in Kuwait prefers to seek treatment in other countries, whether tourism and abuse of power are still relevant after the new regulations, and if the public would prefer alternatives.

\section{Methods}

This cross-sectional study was carried out in 2018. An Arabic questionnaire comprised of 42 questions was constructed based on existing and troublesome public complaints against the Ministry of Health in Kuwait. The authors made an initial draft of the questionnaire which was reviewed and edited by the Treatment Abroad Committee of Kuwait's Department of Health. Then the questionnaire was given to two independent public health physicians to obtain their expert opinions on current state matters. The final draft was produced after a consensus was reached by all physicians involved. A pilot study of 10 people was done, and their feedback was used to improve the survey.

The Medical Council provided the registry of patients who went abroad for treatment (both surgical and non-surgical) in the year 2018. Since all patients who go through the process fall under the same regulations, no exclusions were made. The phone numbers of 1067 patients were obtained, and a Google form was sent to them to complete electronically. Attached to the Google form was a brief description of the contents of the questionnaire and a detailed consent form which participants were asked to sign before proceeding with the questionnaire. A reminder to complete the questionnaire was sent to the patients two weeks later. One month after the initial distribution, 590 responses had been received; only one survey was not correctly completed.

Statistical analyses were performed using R v3.6 software (R Foundation for Statistical Computing Vienna, Austria, 2018), IBM ${ }^{\circledR}$ SPSS $^{\circledR}$ Statistics version 26, and GraphPad Prism v.8. Descriptive statistics were performed using counts and percentages for categorical variables and mean \pm standard deviation for continuous variables. For checkbox questions, the rate for each response was calculated from the total sample size. The chi-square test of independence was implemented to evaluate the relationship between two categorical variables. To investigate the reliability and validity of the questionnaire, first, the unidimensionality of each factor was measured using principal component analysis. ${ }^{15}$ The criterion of Fornell-Larcker was also used to assess the degree of shared variance between the latent variables of the model. AVE (Average Variance Extracted) was used to measure the level of variation captured by a construct versus the standard due to measurement error. Values above 0.7 were considered very good, and the level of 0.5 was acceptable. CR (composite reliability) is a less biased estimate of reliability than Cronbach alpha; the fair value of CR was considered to be 0.7 or higher. ${ }^{16}$ The association between two categorical variables was assessed using the chi-square test of independence. Hypothesis evaluation was done at a 5\% level of importance.

\section{Results}

The study sample included 589 respondents who completed the survey. Therefore, the percentage was calculated based on the number of valid responses for each question.

\section{Survey Validity and Reliability}

In this study, domestic issues in Kuwait, costs of treatment abroad, language barrier, level of complications, and perceived experience abroad were considered to be factors that could determine the attitude of Kuwaitis toward health tourism. To address the unidimensionality of these factors, PCA was performed. Factors with eigenvalues above one were considered, which comprised the core of the survey used in this study (Table 1). ${ }^{15}$

To examine the reliability of each construct, CR was used instead of Cronbach's alpha, as shown in Table 2. All constructs had a CR value higher than 0.7 , which showed 
Table 1. Investigation of Unidimensionality of Each Factor Using Principal Component Analysis

\begin{tabular}{|c|c|c|c|c|c|c|}
\hline Items & Domestic Treatment & Language & Domestic Trust & Experience & Cost & Complication \\
\hline Q9 & 0.779 & & & & & \\
\hline Q10 & 0.750 & & & & & \\
\hline Q17 & & 0.720 & & & & \\
\hline Q22 & & 0.770 & & & & \\
\hline Q26 & & & 0.853 & & & \\
\hline Q28 & & & 0.754 & & & \\
\hline Q29 & & & 0.671 & & & \\
\hline Q24 & & & & 0.824 & & \\
\hline Q27 & & & & 0.798 & & \\
\hline Q30 & & & & 0.753 & & \\
\hline Q31 & & & & 0.700 & & \\
\hline Q35 & & & & 0.680 & & \\
\hline Q40 & & & & 0.720 & & \\
\hline Q44 & & & & 0.736 & & \\
\hline Q32 & & & & & 0.680 & \\
\hline Q33 & & & & & 0.721 & \\
\hline Q34 & & & & & 0.783 & \\
\hline Q36 & & & & & & 0.830 \\
\hline Q39 & & & & & & 0.713 \\
\hline
\end{tabular}

Table 2. CR, the Square Root of the AVE (in bold), and Correlations Between Constructs (Off-Diagonal)

\begin{tabular}{|c|c|c|c|c|c|c|c|c|c|}
\hline ID & Items & AVE & CR & A & B & $\mathrm{C}$ & D & E & $\mathbf{F}$ \\
\hline A & Domestic Treatment & 0.590 & 0.738 & 0.768 & & & & & \\
\hline B & Language & 0.560 & 0.720 & 0.321 & 0.748 & & & & \\
\hline $\mathrm{C}$ & Domestic Trust & 0.600 & 0.810 & 0.430 & 0.419 & 0.775 & & & \\
\hline $\mathrm{D}$ & Experience Abroad & 0.556 & 0.890 & 0.480 & 0.356 & 0.592 & 0.746 & & \\
\hline $\mathrm{F}$ & Complication & 0.600 & 0.750 & 0.200 & 0.520 & 0.423 & 0.540 & 0.256 & 0.775 \\
\hline
\end{tabular}

Abbreviations: CR, composite reliability; AVE, average variance extracted.

acceptable reliability. Moreover, all constructs had more significant AVE values of 0.5 , which is not a perfect, but an acceptable level of measured variance. Since the square root of AVE was higher than the correlations among constructs, it can also be concluded that the constructs had an acceptable level of discriminant validity.

\section{Descriptive Analysis of the Survey}

Based on Table 3, males and females were similarly represented in the research sample (52.3\% and $47.7 \%$, correspondingly). The mean age for the study sample was $41 \pm 13.4$ years.

Approximately half of the respondents (approximately $45.3 \%$ ) were married and had children. Most of the remaining respondents were either married but had no children (21.9\%) or single (23.8\%). All respondents received medical treatment abroad with $52.3 \%$ and $47.7 \%$ stating that they received it once and more than once, respectively. Participants who were treated at the expense of the state were also more likely to respond with "more than once" compared with those who were not $(50.6 \%$ vs. $39 \%, P<0.05)$.

The results showed that $75.2 \%$ of participants received medical treatment abroad at the expense of the state only, and half of them $(49.1 \%)$ received medical treatment abroad at their own cost at least once.

A statistically significant association was observed between source of funding for medical treatment abroad and number of treatment times. Participants treated at their own expense were more likely to respond with "more than once" compared with those who were not $(57.1 \%$ vs. $38.7 \%, P<0.001)$. Participants who were treated at the expense of the state were also more likely to respond with "more than once" compared with those who were not $(50.6 \%$ vs. $39 \%, P<0.05)$.

The results showed that $57 \%$ of the participants were diagnosed in Kuwait compared with only $7 \%$ who were not, 
Table 3. Descriptive Statistics for the Study Sample

\begin{tabular}{lcc}
\hline Demographic Variables & Frequency & Percent \\
\hline Gender & 281 & 47.70 \\
Female & 308 & 52.30 \\
Male & & \\
Age & 26 & 4.50 \\
0-20 & 109 & 18.80 \\
21-30 & 163 & 28.10 \\
31-40 & 136 & 23.40 \\
41-50 & 112 & 19.30 \\
51-60 & 29 & 5 \\
61-70 & 5 & 0.90 \\
>70 & & \\
Marital status & 140 & 23.80 \\
Single & 129 & 21.90 \\
Married & 267 & 45.30 \\
Married with children & 3 & 0.51 \\
Widowed & 13 & 2.21 \\
Widowed with children & 15 & 2.55 \\
Divorced & 22 & 3.74 \\
Divorced with children & & \\
Received medical treatment abroad? & 308 & 52.30 \\
Once & 281 & 47.70 \\
More than once & & \\
\hline
\end{tabular}

and $37 \%$ of the participants received incorrect diagnoses.

When questioned about receiving medical treatment in Kuwaiti hospitals, (25.6\%) of participants stated that the required treatment was not available, (13.2\%) refused treatment, (17.5\%) did not continue with treatment, and (43.1\%) reported that the procedure was not correct. The results shown in Figure 1A show that the main reasons for traveling abroad were to obtain better medical care (49.75\%), and the higher efficiency of medical cadres outside Kuwait (49.41\%). Other reasons included low confidence in medical services in Kuwait (46.86\%), inadequate health facilities (37.35\%), long waiting lists (27.33\%), and non-availability of treatment $(26.99 \%)$. Over $63.3 \%$ of the participants had only one medical problem, while $21.6 \%$ and $8.8 \%$ had two and three medical issues, respectively.

The most commonly reported medical specialties sought were orthopedic surgery (32.6\%), internal medicine (20.88\%), and tumor surgery $(14.94 \%)$. The least reported specialties were mental health $(1.53 \%)$ and blood vein surgery $(2.89 \%)$ (Table 4).

The results showed that there was no statistically significant difference in the distribution of medical problems between males and females ( $P>0.05$ for all comparisons).

Participants were asked about their preference for receiving treatment in a particular country; 62\% responded with "yes" (they preferred a specific country), while $38 \%$ responded with "No" (they had no preference for any country).

As seen in Figure 2A, the United States of America and Germany were the most preferred countries for medical treatment (47.81\% and 44\%, respectively). Britain (30\%), France (15.57\%), and Thailand (12.3\%) came in third, fourth, and fifth place, respectively. Language was not a significant barrier to making a selection, as perceived by $91 \%$ of the participants. Responses were missing for one respondent.

Figure $2 \mathrm{~B}$ shows that the main reasons for the selection of a country were healthcare reputation (64.52\%), recommendations made by doctors $(35.31 \%)$, and previous experiences $(24.45 \%)$. Tourism and nature were selected by (3.4\%) of participants.

The answers to the question about preferred escorts varied among participants, with $22.4 \%$ choosing two people from among relatives, $19.4 \%$ choosing one offspring, and $17.9 \%$ choosing one relative. Other responses included husband/ wife $(15.3 \%)$, a friend $(11.2 \%)$, and father/mother $(5.3 \%)$. One and two escorts were reported by $(41.7 \%)$ and $(39.5 \%)$ participants, respectively. Only 24 (4.1\%) respondents reported having no escorts. Over 50\% reported that the gender of the escort made no difference; $16 \%$ preferred females, and $28 \%$ preferred a male (Figure 3 ).

There was a statistically significant difference in the distribution of responses based on gender $(P<0.001)$. The
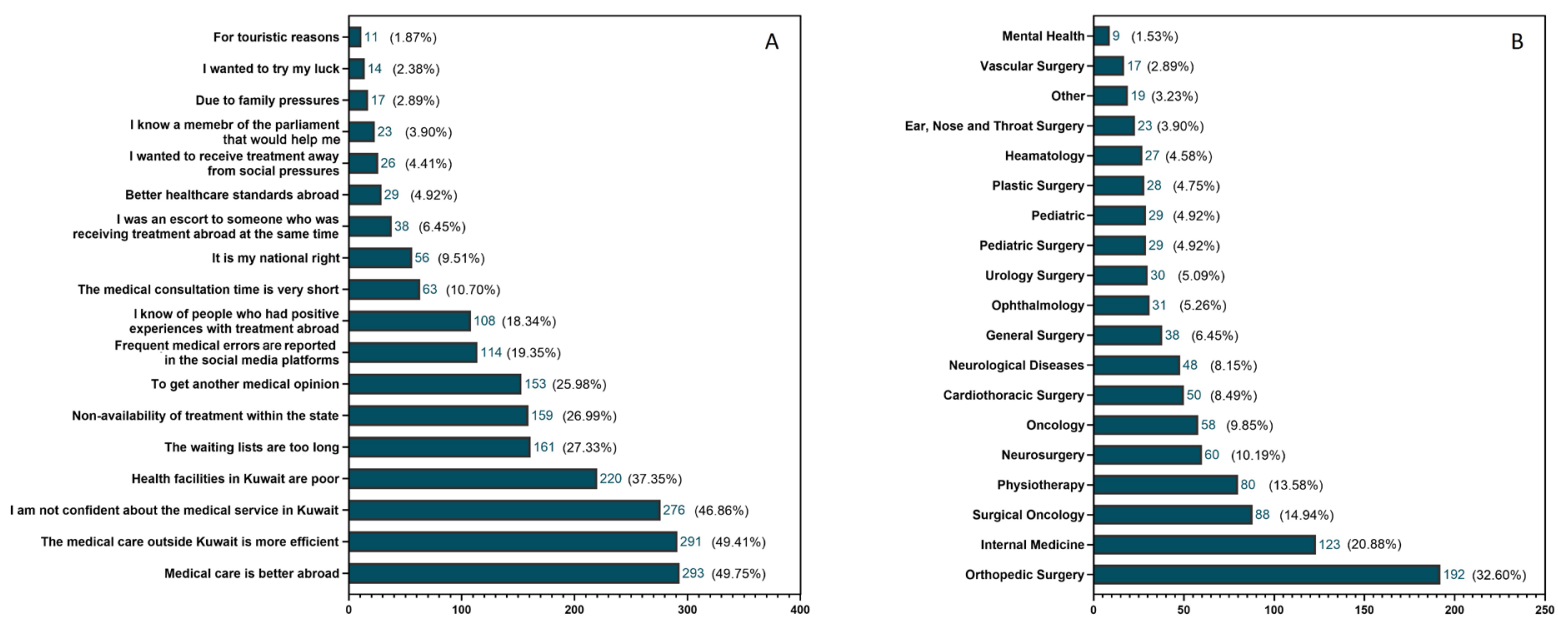

Figure 1. Reasons for Seeking Treatment Abroad (A) and Type of Medical Conditions (B) - Only responses with $\mathrm{n}>10$ are shown; \% were calculated from the total sample size $(n=589)$. 
Table 4. Comparison of Medical Probems Between Males and Females

\begin{tabular}{lccc}
\hline \multirow{2}{*}{ Medical Problem } & Female & Male & \multirow{2}{*}{$\boldsymbol{P}$ Value } \\
\cline { 2 - 3 } Orthopedic surgery & $\mathbf{n}=\mathbf{2 8 1}$ & $\mathbf{n = 3 0 8}$ & \\
Hematology & $12(4.27 \%)$ & $15(4.87 \%)$ & 0.283 \\
Eye surgery & $13(4.63 \%)$ & $18(5.84 \%)$ & 0.634 \\
General surgery & $15(5.34 \%)$ & $23(7.47 \%)$ & 0.377 \\
Urology surgery & $8(2.85 \%)$ & $22(7.14 \%)$ & 0.420 \\
Physiotherapy & $37(13.2 \%)$ & $43(14.0 \%)$ & 0.873 \\
Neurosurgery & $34(12.1 \%)$ & $26(8.44 \%)$ & 0.184 \\
Plastic surgery & $18(6.41 \%)$ & $10(3.25 \%)$ & 0.108 \\
Pediatric & $8(2.85 \%)$ & $21(6.82 \%)$ & 0.420 \\
Internal medicine & $53(18.9 \%)$ & $70(22.7 \%)$ & 0.293 \\
Oncology & $33(11.7 \%)$ & $25(8.12 \%)$ & 0.181 \\
Surgical oncology & $46(16.4 \%)$ & $42(13.6 \%)$ & 0.416 \\
Ear nose and throat surgery & $9(3.20 \%)$ & $14(4.55 \%)$ & 0.531 \\
Cardiothoracic surgery & $19(6.76 \%)$ & $31(10.1 \%)$ & 0.198 \\
Pediatric surgery & $10(3.56 \%)$ & $19(6.17 \%)$ & 0.203 \\
Neurological diseases & $23(8.19 \%)$ & $25(8.12 \%)$ & 1.000 \\
Mental health & $4(1.42 \%)$ & $5(1.62 \%)$ & 1.000 \\
Vascular surgery & $8(2.85 \%)$ & $9(2.92 \%)$ & 1.000 \\
Other & $11(3.91 \%)$ & $8(2.60 \%)$ & 0.503 \\
Interventional radiology & $1(0.36 \%)$ & $0(0.00 \%)$ & 0.477 \\
\hline
\end{tabular}

Statistical analysis was performed using chi-square test of independence.

percentage of females that preferred female escorts was significantly higher than the rate of males, and the opposite was observed for male participants. Over 50\% of the participants mentioned that the treating hospital provided an interpreter (53\%) compared to $13 \%$ that replied with "No." One quarter said that they did not need an interpreter (8\%). The reported trip length varied from two weeks or less $(10.2 \%)$ to one year or more $(5.3 \%)$. The most commonly reported trip length was three to six months (33.3\%). Trip time was reported to be sufficient in $67.5 \%$ of participants and insufficient in the remaining $32.5 \%$ of participants. There was no statistically significant difference in the patients' perception of time sufficiency based on the reported trip length $(P=0.206)$
(Figure 4).

Concerning the number of health problems recorded, only $1.3 \%$ of the participants mentioned that they received treatment that corresponded to their health problem as well as the health problem of their escort. The rest of the participants received treatment for either one (58.2\%) or at least one health problem (40.5\%) (Figure 5).

The results indicated that $30.3 \%$ of the respondents had confidence in Kuwait's general medical capabilities, while $69.7 \%$ did not; however, the greater majority did not regret the decision to be treated abroad (96\%). Of the respondents, $64.3 \%$ wanted to return to Kuwait earlier, and 56\% said they would not have gone for treatments abroad had the attending doctor been available in Kuwait. The responses further showed a positive attitude towards treatment abroad, as shown by the high percentage of participants $(86.7 \%)$ that would consider seeking treatment abroad again. The greater majority of respondents (95.8\%) thought that they needed treatment abroad, and only $66.3 \%$ of the respondents looked for the attending doctor's reports before traveling.

If the means for receiving medical treatment abroad had not been provided by the state, $38.4 \%$ of respondents would

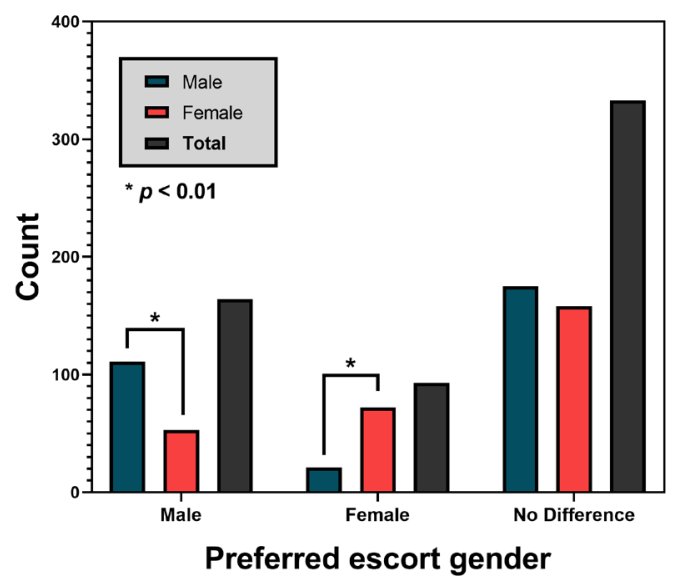

Figure 3. Escort Preferences Based on Gender.

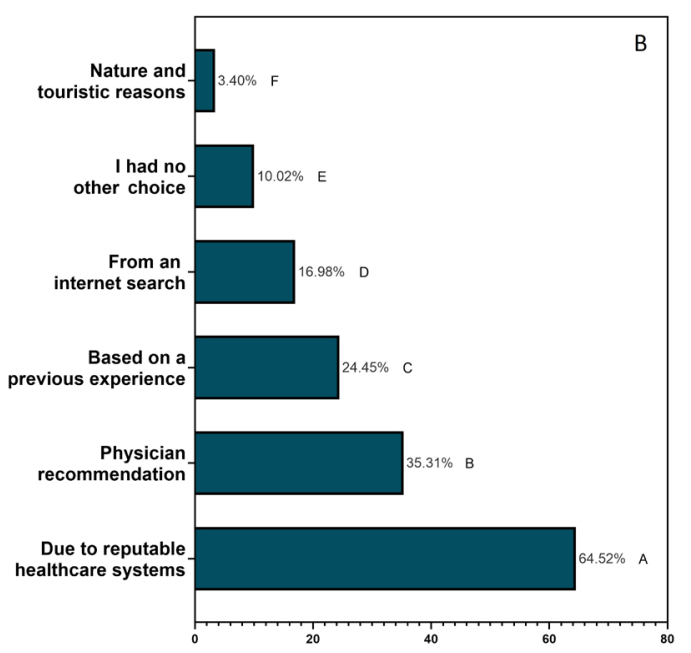

Figure 2. Preferred Country for Medical Treatment (A, Percentage was calculated from participants that had a specific preference, $\mathrm{n}=366$ ) and Reasons for Selection of a Country (B, Percentage was calculated from the total number of participants, $n=589$ ). 


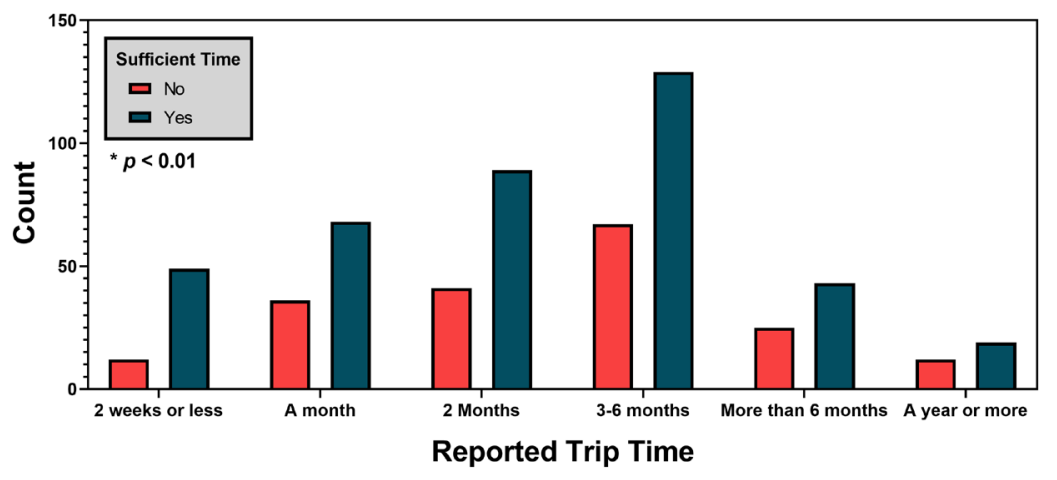

Figure 4. Sufficiency of Time Based on Trip Length.

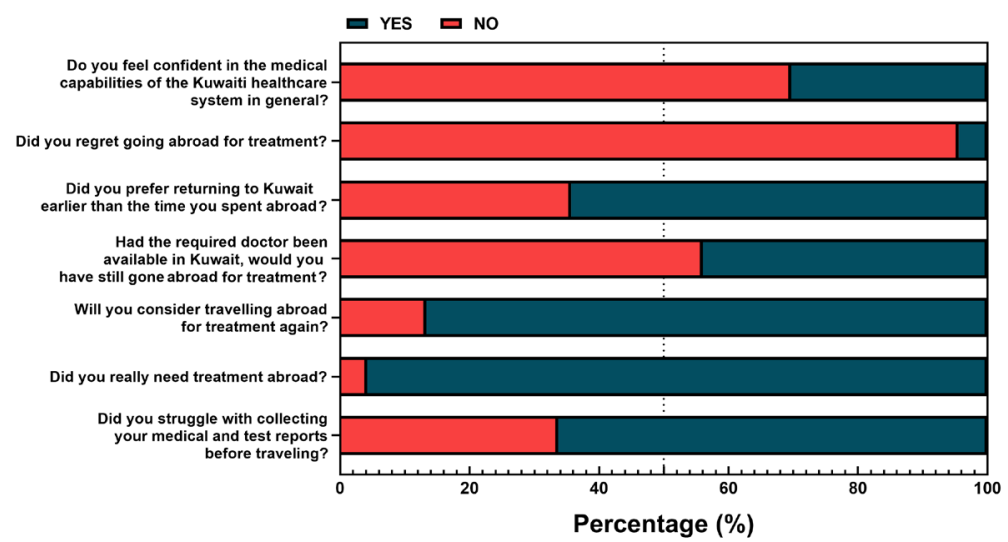

Figure 5. Responses to Yes/No Questions Related to Medical Travel.

have traveled at their own expense, while $57.5 \%$ would have done so if they had resources, and only $4.08 \%$ would not have traveled. The funds provided by the state covered the basic expenses as perceived by $56.1 \%$ of the participants and were in excess of the minimum requirement as perceived by $8.67 \%$ of the participants. However, according to $23.3 \%$ of the participants, the expenditures were insufficient (Table 5).

The results, shown in Figure 6, showed that the majority of participants (84.18\%) did not stay long after completing their medical treatment, but some stayed longer as tourists (5.44\%) or for the treatment of their escort (10.37\%). In addition, the responses showed that $32.48 \%$ of the participants perceived the application process as a lengthy one and $22.79 \%$ of them did not. The remaining participants (44.73\%) responded with "Yes, through intermediaries." Moreover, at least 50\% of the participants reported no complications during or after treatment $(\mathrm{n}=365,62.07 \%)$, while simple, predictable, and severe complications (affected life or required intensive care) occurred in $30.44 \%$ and $7.48 \%$ of participants, respectively. As reported by $25.9 \%$ of the respondents, the travel experience was convenient, but the rest of the participants (74.2\%) mentioned that their experience was frustrating, because they were away from relatives and their homeland. The majority of respondents $(62.99 \%)$ mentioned that they returned to their accommodations after completing the treatment/follow up. Other activities reported included sightseeing or taking a walk (39.73\%) and shopping (20.37\%), while some respondents
(16.3\%) never left the hospital throughout the treatment.

As shown in Table 6, about $45.1 \%$ of the participants followed up in a governmental hospital after their treatment was complete, $16.5 \%$ went back to the country where they received treatment, $19 \%$ followed up in a private hospital, and the remaining participants (19.4\%) never followed up. More than half $(68.5 \%)$ of the participants reported having no insurance, while others $(10.7 \%)$ had medical insurance (AFIA), retiree insurance (17.9\%) for people over than 65 paid fully by the government, or had insurance but did not use it (2.89\%). Moreover, $61.22 \%$ of the participants did not prefer having a nurse during the trip, $31.29 \%$ preferred having a special nurse at the expense of the state, and $7.48 \%$ preferred having a nurse at their own personal expense.

\section{Discussion}

Because of the rise in medical tourism, it is believed that global public health systems will be negatively impacted; the growing importance of medical tourism notwithstanding, there is not much evidence of its impact on health systems. ${ }^{14}$ The medical communities in host countries have begun to recognize medical tourism as a phenomenon that has great impacts on the medical profession, medical practitioners, and patients, ${ }^{17}$ which implies that the limited statistical data on medical tourism cannot be compared across countries, even though the observations available suggest that a substantial number of patients seek healthcare abroad. For instance, in 
Table 5. Expenditures for Medical Treatment Abroad

\begin{tabular}{ll}
\hline Questions & No. $(\%)$ \\
\hline Travel at personal expenses if not provided by state? & $24(4.08)$ \\
No & $338(57.5)$ \\
Yes, but no resources & $226(38.4)$ \\
Sufficient expenditures & \\
It was at my personal expense & $66(11.9)$ \\
No & $137(23.3)$ \\
Yes, and more & $51(8.67)$ \\
Yes, as needed & $330(56.1)$ \\
State expenditures allocated & \\
KD 100 to 500 & $75(12.6)$ \\
KD 500 to 1000 & $66(11.2)$ \\
KD 1000 to 3000 & $122(20.7)$ \\
KD 3000 to 5000 & $93(15.3)$ \\
KD 5000 to 10000 & $71(12.1)$ \\
KD 10000 to 20000 & $51(8.33)$ \\
More than KD 20000 & $46(7.82)$ \\
It was at my personal expense & $66(11.9)$ \\
\hline
\end{tabular}

2007, 360000 foreigners from the Association of Southeast Asian Nations (ASEAN) visited Malaysia for healthcarerelated purposes. ${ }^{12}$ The literature attributes this to the fall in the number of privatized hospitals in countries such as Canada and the UK, and the subsequent increase in the medical market influx between countries. ${ }^{18-20}$ This could be the reason why places like India, Malaysia, and Thailand are increasingly becoming well-known medical hubs, and thus attracting patients, especially from the west, who feel that their national healthcare systems have failed..$^{21-23}$

The current study shows that the United States was the most visited and preferred medical tourism destination for the survey participants, and thus accounted for $47.81 \%$ of medical tourism visits. It was closely followed by Germany at $44 \%$. The driving motivators for this include the availability of advanced medical technology, as reported by $64.52 \%$ of the respondents, as well as highly qualified and sophisticated physicians. ${ }^{23}$ This is quite unlike a study in Saudi Arabia which
Table 6. Follow up, and Insurance Status of the Respondents

\begin{tabular}{lr}
\hline & No. (\%) \\
\hline Where did you follow up after treatment abroad? & $265(45.1)$ \\
Government hospital & $97(16.5)$ \\
I went back to the country where I received treatment at my & \\
personal expense & $114(19.4)$ \\
I never followed up anywhere & $112(19.0)$ \\
Private hospital & \\
Do you have medical insurance? & $403(68.5)$ \\
No & $63(10.7)$ \\
Yes & $17(2.89)$ \\
Yes, but I don't use it & $105(17.9)$ \\
\hline Yes, I have AFIA insurance
\end{tabular}

reported that $49 \%$ of patients preferred Pakistan as their destination for renal transplants, followed by the Philippines at $28 \%$, Egypt at $11 \%$, and the United States at 3.2\%. ${ }^{24}$ Patients in Oman, however, were reported to have visited Thailand and India as their top destinations for medical treatment. ${ }^{25}$

Fifty-three percent of the participants selected pure tourism as their intention to go abroad, while atmosphere and nature were selected by $1.87 \%$ of the participants. Oman's healthcare system, which is similar to that of Kuwait, reported that $10 \%$ of their patients go abroad for tourism. ${ }^{25}$ This low tourism figure might be attributable to the fact that participants in the current study went abroad for the primary purpose of healthcare and then decided to tour the host country at the same time. The reason American citizens travel abroad for treatment, however, is mainly tourism. A study by Deloitte Consulting estimated that up to 750000 Americans sought healthcare services abroad in 2007; this figure rose to 1.6 million in 2012. ${ }^{13}$ However, unlike the current study population, these medical travelers were self-sponsored, not governmentally funded. ${ }^{13}$ The leading reason for Kuwaitis traveling abroad for medical treatment (69.7\%) was that the patients had no confidence in Kuwait's general medical capabilities. As a result, about $34 \%$ of the traveling populace never sought their doctor's assessment before traveling. This reflects a positive attitude towards treatment abroad, since about $89 \%$ of the survey takers in the current study would repeat their experience.
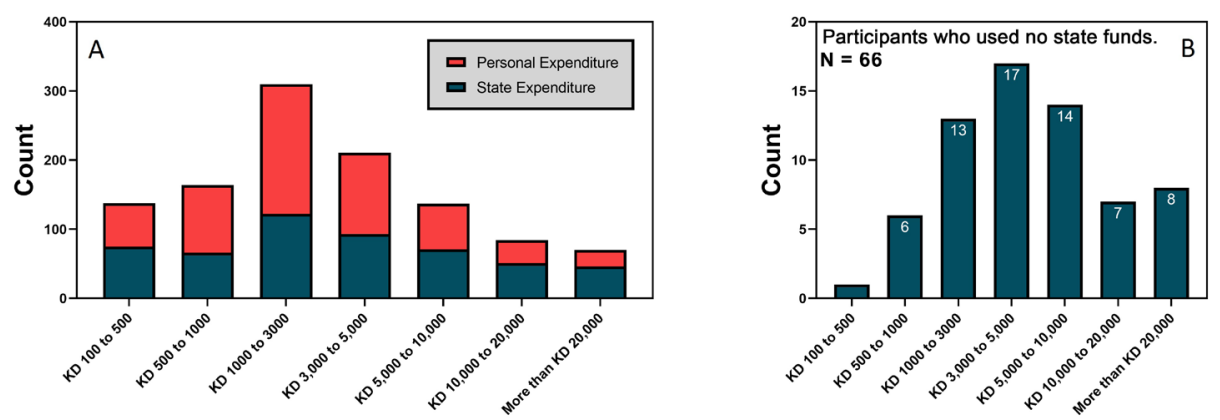

Figure 6. State and Personal Expenditures During Medical Treatment Abroad. (A) Participants who covered their expenses by state and personal funds; (B) Participants who went abroad solely on their personal accounts. 
A study covering reproductive health tourism in Saudi Arabia hinted that another purpose for travel is privacy, and it is of great importance in an environment where in vivo fertilization and infertility are frowned upon..$^{25,26}$ In this study, about $4 \%$ of the participants stated that they would choose medical treatment abroad, because they sought privacy. Although it is a general belief that medical care abroad is cheap, the general costs are high, and the financial implications could be detrimental for the country's economy; however, the economic growth in hosting counties has been estimated to reach $26.8 \%$ by the current literature.

About $30 \%$ of the participants experienced simple, predictable complications, while $7.48 \%$ had severe complications. The authors believe that this might be an underestimation since most people tend not to report problems, so it does not decrease their chances of receiving outbound medical treatment again. However, almost the same number of complications was observed in a UK study. ${ }^{25,26}$ A 2010 study by Alghamdi et al showed that transplant tourists experienced a higher rate of acute rejection within the first 12 months compared with those who choose local transplantation $(27.9 \%$ versus $9.9 \%, P=0.005) .^{24}$ It should also be noted that orthopedics was the most popular specialty for which Kuwaitis sought overseas medical care; this was in keeping with the Omani study. ${ }^{25} \mathrm{~A}$ most interesting fact about Oman's study was that $15 \%$ of the respondents did not seek local medical care before going abroad for medical care, yet the number of Kuwaitis who conducted this same behavior was almost double that of the Omanis. ${ }^{25}$

Although it is difficult to measure intent and behavioral reasons for seeking overseas treatment, ${ }^{29-31}$ there is a small number of people among the Kuwaiti population who have a sense of entitlement reflected in the reasons the participants selected other than the $1.87 \%$ who wanted to go for tourism. Attitudes like the waiting times are too long (27.3\%), fear of medical errors reported in social media platforms (19.3\%), short consultation time (10.7\%), and nepotism 3.9\% are attitudes that require further examination as well as the shortcomings of the healthcare system itself, as was done in the United Arab Emirates, which is now showing promising economic growth from inbound medical tourism. ${ }^{32}$

\section{Limitations}

A major limitation of this study was the scarcity of statistics and data on patients who sought medical care overseas, because the governing authorities did not release the exact number of patients who received medical treatment abroad. Another limitation was the scarcity of scientific literature on medical tourism in the Arabian Gulf and Arab countries.

\section{Conclusion}

A lot of money is invested in Kuwait's healthcare systems, but the nationals have become victims of political corruption that has led to national debt with other countries. The majority of Kuwaiti nationals who seek healthcare overseas distrust the healthcare system in Kuwait, but half of them are open to alternatives if they were made available in Kuwait. This

\section{Research Highlights}

What Is Already Known?

Medical tourism has been increasing exponentially in Kuwait and effecting the training of Doctors, and the financial status of the health sectors, however reasons of this is clearly known.

\section{What This Study Adds?}

This study provides a clear insight to medical tourism from the patients point of view and to develop a plan to increase the trust of the patients to system and the health sector.

study provides feedback to major stakeholders in Kuwait's healthcare system to develop the best strategies addressing the direct healthcare needs of this country.

\section{Recommendations}

The issues raised in this Kuwaiti study can be tackled using two different recommendations, namely, community approach and public health sector approach. The goal should be to create awareness among the members of the public using different media in order to sensitize them to medical tourism and its impact on families, countries, communities, and individuals. The authors of this study also recommend that standards should be set to regulate the medical tourism industry in both the country of origin and the country of destination. Medical tourism companies should be accredited, and such accreditation should be reviewed regularly. The country should also invest in its healthcare system by inviting visiting doctors to treat the public and teach the residing staff.

\section{Authors' Contributions}

All the authors contributed equally to this study.

\section{Conflict of Interest Disclosures}

The authors declare that they have no conflicts of interest associated with this study.

\section{Ethical Approval}

This study was approved by the medical ethical committee of Kuwait's Ministry of Health. All patients provided consent prior to completing the questionnaire.

\section{Funding/Support}

None.

\section{References}

1. Connell J. Medical tourism: Sea, sun, sand and ... surgery. Tour Manag. 2006;27(6):1093-1100. doi:10.1016/j.tourman.2005.11.005.

2. Helble M. The movement of patients across borders: challenges and opportunities for public health. Bull World Health Organ. 2011;89(1):68-72. doi:10.2471/blt.10.076612.

3. Crooks VA, Kingsbury P, Snyder J, Johnston R. What is known about the patient's experience of medical tourism? a scoping review. BMC Health Serv Res. 2010;10:266. doi:10.1186/14726963-10-266. 
4. Johnston R, Crooks VA, Snyder J, Kingsbury P. What is known about the effects of medical tourism in destination and departure countries? a scoping review. Int J Equity Health. 2010;9:24. doi:10.1186/1475-9276-9-24.

5. Kuwait Endorses New Regulations for Treatment Abroad. Kuwait Times. 2016. https://news.kuwaittimes.net/website/kuwait-endorses-new-regulations-for-treatment-abroad/. Accessed 3 November 2019.

6. Panel Rejects Proposal to Prevent Overseas Medical Treatment. Arab Times. 2019. https://www.arabtimesonline.com/news/ panel-rejects-proposal-to-prevent-overseas-medical-treatment/. Accessed 24 December 2019.

7. Al-Sarraf A. Treatment Abroad or Tourism? Kuwait Times. 2015. https://news.kuwaittimes.net/website/treatment-abroad-ortourism/. Accessed 3 November 2019.

8. Jouhar H. Cost of Overseas Treatment. Kuwait Times; 2017. https:// news.kuwaittimes.net/website/cost-overseas-treatment/. Accessed 3 November 2019].

9. Politics of Treatment Abroad for Kuwaitis. International Medical Travel Journal. 2019. https://www.imtj.com/news/politicstreatment-abroad-kuwaitis/. Accessed 3 November 2019.

10. Martínez Álvarez M, Chanda R, Smith RD. The potential for bilateral agreements in medical tourism: a qualitative study of stakeholder perspectives from the UK and India. Global Health. 2011;7:11. doi:10.1186/1744-8603-7-11.

11. Snyder J, Dharamsi S, Crooks VA. Fly-By medical care: conceptualizing the global and local social responsibilities of medical tourists and physician voluntourists. Global Health. 2011;7:6. doi:10.1186/1744-8603-7-6.

12. Whittaker A. Pleasure and pain: medical travel in Asia. Glob Public Health.2008;3(3):271-290.doi:10.1080/17441690701463936.

13. Medical Tourism Consumers in Search of Value. Deloitte Center for Health Solutions. http://www.deloitte.com/assets/ Dcom-UnitedStates/Local\%20Assets/Documents/us_chs_ MedicalTourismStudy(3).pdf. Accessed October 2019.

14. Lang WL. Health Care Abroad. In: Travel Medicine. Elsevier; 2019: 475-481. doi:10.1016/B978-0-323-54696-6.00053-7. Accessed October 2019.

15. Hagell P. Testing rating scale unidimensionality using the principal component analysis (PCA)/t-test protocol with the Rasch model: the primacy of theory over statistics. Open J Stat. 2014;4(6):456465. doi:10.4236/ojs.2014.46044.

16. Fornell C, Larcker DF. Evaluating structural equation models with unobservable variables and measurement error. J Mark Res. 1981;18(1):39-50. doi:10.2307/3151312.

17. Ehrbeck T, Guevara C, Mango PD. Mapping the Market for Medical Travel. McKinsey Quarterly. 2008. https://www.mckinseyquarterly. com/Mapping_the_market_for_travel_2134. Accessed October
2019.

18. Collins A, Medhekar A, Wong HY, Cobanoglu C. Factors influencing outbound medical travel from the USA. Tour Rev. 2019;74(3):463-479. doi:10.1108/TR-06-2018-0083.

19. Lunt N, Horsfall D, Hanefeld J. Medical tourism: a snapshot of evidence on treatment abroad. Maturitas. 2016;88:37-44. doi:10.1016/j.maturitas.2016.03.001.

20. Ormond M, Sulianti D. More than medical tourism: lessons from Indonesia and Malaysia on South-South intra-regional medical travel. Curr Issues Tour. 2014;20(1):94-110. doi:10.1080/136835 00.2014 .937324$.

21. Horowitz MD, Rosensweig JA, Jones CA. Medical tourism: globalization of the healthcare marketplace. MedGenMed. 2007;9(4):33.

22. Eggertson L. Wait-list weary Canadians seek treatment abroad. CMAJ. 2006;174(9):1247. doi:10.1503/cmaj.060219.

23. Alghamdi SA, Nabi ZG, Alkhafaji DM, et al. Transplant tourism outcome: a single center experience. Transplantation. 2010;90(2):184-188. doi:10.1097/TP.0b013e3181e11763.

24. Al-Hinai SS, Al-Busaidi AS, Al-Busaidi IH. Medical tourism abroad: a new challenge to Oman's health system-Al Dakhilya region experience. Sultan Qaboos Univ Med J. 2011;11(4):477-484.

25. Bovier PA. [Medical tourism: a new kind of traveler?]. Rev Med Suisse. 2008;4(157):1196, 1198-1201.

26. Inhorn MC, Shrivastav P. Globalization and reproductive tourism in the United Arab Emirates. Asia Pac J Public Health. 2010;22(3 Suppl):68S-74S. doi:10.1177/1010539510373007.

27. Liang LJ, Choi HC, Joppe M, Lee W. Examining medical tourists' intention to visit a tourist destination: application of an extended MEDTOUR scale in a cosmetic tourism context. Int J Tour Res. 2019;21(6):772-784. doi:10.1002/jtr.2303.

28. Johnston R, Crooks VA, Adams K, Snyder J, Kingsbury P. An industry perspective on Canadian patients' involvement in medical tourism: implications for public health. BMC Public Health. 2011;11:416. doi:10.1186/1471-2458-11-416.

29. Turner L. Medical tourism: family medicine and international health-related travel. Can Fam Physician. 2007;53(10):1639-1641, 1646-1638.

30. Rotem A, Toker A, Mor-Yossef S. [Medical tourism: changing a world trend into a national resource]. Harefuah. 2009;148(1):30$33,88$.

31. Van Dusen A. U.S. Hospitals Worth the Trip. Forbes. 2008. https:// www.forbes.com/2008/05/25/health-hospitals-care-forbeslife-cx_ avd_outsourcing08_0529healthoutsourcing.html\#13bea16452e1.

32. Al-Talabani H, Kilic H, Ozturen A. Qasim SO. Advancing medical tourism in the United Arab Emirates: toward a sustainable health care system. Sustainability. 2019;11(1):230. doi:10.3390/ su11010230. 